\title{
Prevalence of significant carotid artery stenosis in Iranian patients with peripheral arterial disease
}

This article was published in the following Dove Press journal:

Vascular Health and Risk Management

10 October 2011

Number of times this article has been viewed

\author{
Abolhassan Shakeri Bavil' \\ Kamyar Ghabili² \\ Seyed Ebrahim Daneshmand ${ }^{3}$ \\ Masoud Nemati ${ }^{3}$ \\ Moslem Shakeri Bavil ${ }^{4}$ \\ Hossein Namdar ${ }^{5}$ \\ Sheyda Shaafi ${ }^{6}$ \\ 'Tuberculosis and Lung Disease \\ Research Center, Tabriz University of \\ Medical Sciences, Tabriz, Iran; ${ }^{2}$ Medical \\ Philosophy and History Research \\ Center, Tabriz University of Medical \\ Sciences, Tabriz, Iran; ${ }^{3}$ Department of \\ Radiology, Tabriz University of Medical \\ Sciences, Tabriz, Iran; ${ }^{4}$ Department \\ of Neurosurgery, Tabriz University \\ of Medical Sciences, Tabriz, Iran; \\ ${ }^{5}$ Department of Cardiology, Tabriz \\ University of Medical Sciences, Tabriz, \\ Iran; ${ }^{6}$ Neuroscience Research Center, \\ Tabriz University of Medical Sciences, \\ Tabriz, Iran
}

Correspondence: Sheyda Shaafi Neuroscience Research Center, Tabriz University of Medical Sciences, Tabriz, Iran

$\mathrm{Tel} / \mathrm{Fax}+989143116203$

Email shaafis@tbzmed.ac.ir
Background: Generalized screening for carotid artery stenosis with carotid duplex ultrasonography in patients with peripheral arterial disease is controversial.

Objectives: The aim of the present study was to determine the prevalence of significant internal carotid artery (ICA) stenosis in a group of Iranian patients with peripheral arterial disease.

Methods: We prospectively screened 120 patients with a known diagnosis of peripheral vascular disease for carotid artery stenosis. Based on the angiographic assessment of abdominal aorta and arteries of the lower extremities, patients with stenosis greater than $70 \%$ in the lower extremity arteries were included. A group of healthy individuals aged $\geq 50$ years was recruited as a control. Risk factors for atherosclerosis including smoking, diabetes mellitus, hyperlipidemia, ischemic heart disease, and cerebrovascular disease were recorded. Common carotid arteries (CCAs) and the origins of the internal and external arteries were scanned with B-mode ultrasonogaphy. Significant ICA stenosis, $>70 \%$ ICA stenosis but less than near occlusion of the ICA, was diagnosed when the ICA/CCA peak systolic velocity ratio was $\geq 3.5$.

Results: Ninety-five patients, with a mean age of 58.52 \pm 11.04 years, were studied. Twenty-five patients had a history of smoking, six patients had a history of coronary artery disease, six patients had hypertension, and ten patients had diabetes mellitus. Significant ICA stenosis was present in four patients $(4.2 \%)$ with peripheral arterial disease in one healthy individual $(1 \%)$ of the control group $(P>0.05)$. In terms of the risk factors for atherosclerosis, no statistically significant relationship was found between individual atherosclerotic risk factors and significant ICA stenosis $(P>0.05)$.

Conclusion: The prevalence of significant ICA stenosis in Iranian patients with peripheral arterial disease is low. In addition, there is no relationship between individual atherosclerotic risk factors and significant ICA stenosis.

Keywords: carotid artery stenosis, atherosclerosis, peripheral arterial disease, Iranian

\section{Introduction}

Stroke represents one of the major public health problems worldwide. Carotid atherosclerosis is associated with a risk of stroke. This increases with the severity of the stenosis. ${ }^{1}$ Asymptomatic Carotid Atherosclerosis Study (ACAS) demonstrated the benefit of performing carotid endarterectomy in selected asymptomatic patients with significant carotid artery stenoses $(>60 \%$ stenosis $){ }^{2}$ It therefore becomes clinically important to identify the subgroups of patients who have a sufficiently high incidence of high-grade carotid stenosis to warrant routine carotid duplex screening.

Patients with symptomatic peripheral arterial disease often have manifestations of atherosclerosis elsewhere, especially in the cerebrovascular system. ${ }^{3}$ Several studies 
have reported that the prevalence of asymptomatic carotid artery stenosis is quite high in patients with peripheral arterial disease ${ }^{4-7}$ therefore, routine carotid duplex ultrasonography has been recommended in these patients. However, generalized screening in patients with peripheral arterial disease is controversial and the cost-effectiveness remains to be demonstrated. ${ }^{8}$ In Iran, the prevalence of asymptomatic internal carotid artery (ICA) stenosis in patients with peripheral arterial disease has not yet been reported. Therefore, the aim of the present study was to determine the prevalence of significant ICA stenosis in a group of Iranian patients with peripheral arterial disease.

\section{Methods}

We prospectively screened 120 patients with a known diagnosis of peripheral vascular disease for carotid artery stenosis between June 2005 and May 2009. Only patients with uncomplicated lower extremity ischemia referred to our vascular laboratory by vascular surgeons were included. All patients in the study had peripheral arterial disease diagnosed based on the appropriate clinical history and examination followed by conventional angiography. ${ }^{9,10}$ Subjects with any history of neurological symptoms, previous stroke, or previous carotid endarterectomy were excluded. A group of healthy individuals aged $\geq 50$ years was recruited as a control. The control group had no risk factors for atherosclerosis. All selected subjects were asked to complete a questionnaire in which the following risk factors for atherosclerosis were recorded as present or absent: smoking, diabetes mellitus, hyperlipidemia, ischemic heart disease, and cerebrovascular disease. Based on the angiographic assessment of abdominal aorta and arteries of the lower extremities, patients with stenosis greater than $70 \%$ in the lower extremity arteries were included.

The carotid arteries were evaluated with high resolution B-mode ultrasonogaphy, Hitachi EUB.525 ultrasound machine (Hitachi Medical Corp, Tokyo, Japan), with a $7.5 \mathrm{MHz}$ linear-array transducer to evaluate the presence and site of plaques and to qualify the degree of stenosis. ${ }^{1-14}$ The present study involved scanning common carotid arteries (CCAs) and the origins of the internal and external arteries. Significant ICA stenosis, $>70 \%$ ICA stenosis but less than near occlusion of the ICA, was diagnosed when the ICA/CCA peak systolic velocity (PSV) ratio was $\geq 3.5 .{ }^{15,16}$

Data were presented as mean \pm standard deviation (SD) or percentage. Statistical analysis was performed with SPSS for windows (v 13.0; SPSS Inc, Chicago, IL) using chi-square test and Fisher's exact test, whenever appropriate. A $P$ value $<0.05$ was considered statistically significant.

\section{Results}

Ninety-five patients, $81(85.3 \%)$ men and $14(14.7 \%)$ women, with significant peripheral arterial disease of the lower extremities were included in the present study. Fifteen patients were excluded due to the stenosis of $<70 \%$ in the lower extremity arteries. A group of 100 healthy individuals was included as a control. The mean age of the patients was $58.52 \pm 11.04$ years. Twenty-five patients $(26.3 \%)$ had a history of smoking, six patients $(6.3 \%)$ had a history of coronary artery disease, six patients $(6.3 \%)$ had hypertension, and ten patients $(10.5 \%)$ had diabetes mellitus. The control group had no risk factors for atherosclerosis.

Significant ICA stenosis was present in four patients $(4.2 \%)$ with peripheral arterial disease in one healthy individual $(1 \%)$ of the control group $(P>0.05)$. In terms of the risk factors for atherosclerosis, no statistically significant relationship was found between individual atherosclerotic risk factors and significant ICA stenosis $(P>0.05)$.

\section{Discussion}

The present study revealed a low prevalence $(\sim 4 \%)$ of significant ICA stenosis in a group of Iranian patients with peripheral arterial disease. This finding is in contrast to that of previous studies disclosing a prevalence of greater than $70 \%$ carotid stenosis ranging $5 \%-24 \%$ in patients suffering from peripheral vascular disease. ${ }^{4-6,8,17-23}$ In a meta-analysis of nineteen studies, Ahmed and Al-Khaffaf concluded that prevalence of $>70 \%$ asymptomatic carotid artery stenosis was $14 \%$ in patients with peripheral vascular disease. ${ }^{7}$ This discrepancy may be explained by the fact that asymptomatic significant carotid stenosis occurs in elderly patients (age $\geq 65$ years) with peripheral vascular disease. .,6,8,17,20,21 However, the mean age of the patients in the present study was lower ( $\sim 58$ years).

Although different phenotypes of carotid artery atherosclerosis including intima-media thickness, total crosssectional area of carotid plaques, or severity of carotid artery stenosis can be evaluated by ultrasonography, they represent different stages of atherogenesis. ${ }^{24,25}$ On the other hand, compensatory enlargement of the carotid arteries might occur in response to arterial wall thickening and plaque progression. ${ }^{26}$ Therefore, carotid stenosis should not be clinically regarded as the only indicator of cerebrovascular events. Altogether, further studies with other noninvasive modalities such as computed tomography and magnetic resonance imaging are recommended to determine the prevalence of carotid artery atherosclerosis in patients with peripheral arterial disease. 
In terms of the risk factors for atherosclerosis, no statistically significant relationship was found between individual atherosclerotic risk factors and significant carotid artery stenosis. This finding concurs with a number of previous reports. ${ }^{4,17,20}$ In contrast, the majority of the previous studies found a link between age, as a predicting risk factor, and asymptomatic significant carotid artery stenosis. $5,6,8,21,23,27,28$ Alexandrova et al found significant correlations between all risk factors (sex, age, diabetes mellitus, smoking, and hypertension) and the disease severity. ${ }^{5}$ Simons et $\mathrm{al}^{28}$ and Kurvers et $\mathrm{al}^{23}$ indicated a significant association between low diastolic blood pressure and carotid artery stenosis. Recently, Yun and colleagues found that critical ICA stenosis was more common in patients with coronary artery disease. ${ }^{8}$ It is possible that the number of patients in the present study was not large enough to determine a relationship between individual risk factors and significant carotid artery stenosis. However, none of the above studies reported a high enough correlation with individual risk factors to be able to recommend limiting carotid artery disease screening to specific subgroups of patients. ${ }^{20}$

There were few previous studies in Iran on extracranial carotid stenosis in asymptomatic high-risk groups. Nonetheless, these studies were all performed on patients who were candidates for coronary artery bypass graft (CABG). Shirani et al found $>60 \%$ carotid artery stenosis in $7 \%$ of the $\mathrm{CABG}$ candidates with a mean age of 60 years. ${ }^{29} \mathrm{~A}$ later study by Shirani et al indicated $>70 \%$ carotid artery stenosis in $4 \%$ of the CABG candidates..$^{30}$ Two previous studies on CABG candidates in our institution highlighted $>70 \%$ carotid artery stenosis in $1 \%-2 \%$ of the patients. ${ }^{31,32}$ To the best of our knowledge, the present study is the first investigation to assess the prevalence of significant carotid artery stenosis in Iranian patients with peripheral arterial disease.

The problem with peripheral arterial atherosclerosis extends beyond the lower extremities. Patients with peripheral arterial disease of the lower extremities often have widespread atherosclerosis of the arterial beds including coronary artery disease, cerebrovascular disease, and renal artery stenosis. ${ }^{33,34}$ Carotid artery stenosis is a major cause of ischemic stroke and results from large studies have established the efficacy of carotid endarterectomy in stroke prevention in patients with asymptomatic high-grade ICA stenosis. ${ }^{2,35-37}$ Moreover, medical treatment including anticoagulation or antiplatelet agents is a reasonable alternative to carotid endarterectomy in patients who have asymptomatic carotid stenosis. The benefit of carotid endarterectomy, however, has to be interpreted with caution, and the indication for surgery of asymptomatic ICA stenosis is still a matter of debate..$^{38}$
In conclusion, it seems that the prevalence of significant ICA stenosis in Iranian patients with peripheral arterial disease is low. In addition, there is no relationship between individual atherosclerotic risk factors and significant ICA stenosis.

\section{Disclosure}

The authors report no conflicts of interest in this work.

\section{References}

1. Beneficial effect of carotid endarterectomy in symptomatic patients with high-grade carotid stenosis. North American Symptomatic Carotid Endarterectomy Trial Collaborators. N Engl J Med. 1991;325: 445-453.

2. Endarterectomy for asymptomatic carotid artery stenosis. Executive Committee for the Asymptomatic Carotid Atherosclerosis Study. JAMA. 1995;273:1421-1428.

3. Criqui MH, Langer RD, Fronek A, et al. Mortality over a period of 10 years in patients with peripheral arterial disease. $N$ Engl J Med. 1992;326:381-386.

4. Klop RB, Eikelboom BC, Taks AC. Screening of the internal carotid arteries in patients with peripheral vascular disease by colour-flow duplex scanning. Eur J Vasc Surg. 1991;5:41-45.

5. Alexandrova NA, Gibson WC, Norris JW, Maggisano R. Carotid artery stenosis in peripheral vascular disease. J Vasc Surg. 1996;23: 645-649.

6. Cheng SW, Wu LL, Lau H, Ting AC, Wong J. Prevalence of significant carotid stenosis in Chinese patients with peripheral and coronary artery disease. Aust N Z J Surg. 1999;69:44-47.

7. Ahmed B, Al-Khaffaf H. Prevalence of significant asymptomatic carotid artery disease in patients with peripheral vascular disease: a meta-analysis. Eur J Vasc Endovasc Surg. 2009;37:262-271.

8. Yun WS, Rho YN, Park UJ, Lee KB, Kim DI, Kim YW. Prevalence of asymptomatic critical carotid artery stenosis in Korean patients with chronic atherosclerotic lower extremity ischemia: is a screening carotid duplex ultrasonography worthwhile? J Korean Med Sci. 2010;25:1167-1170.

9. Shakeri A, Tubbs RS, Shoja MM, Ghabili K, Hashemzadeh S, Oakes WJ. Analysis of the profunda femoris artery with superficial femoral artery occlusive disease. Biomed Int. 2010;1:62-65.

10. Shakeri AB, Tubbs RS, Shoja MM, Ghabili K, Rahimi-Ardabili B, Loukas M. Screening for thoracoabdominal aortic aneurysms in patients with aortoiliac atherosclerosis: a preliminary study. Folia Morphol (Warsz). 2008;67:78-83.

11. Ghabili K, Khosroshahi HT, Shakeri A, Tubbs RS, Bahluli A, Shoja MM. Can Doppler ultrasonographic indices of the renal artery predict the presence of supernumerary renal arteries? Transplant Proc. 2009;41:2731-2733.

12. Ardalan MR, Shoja MM, Tubbs RS, Ghabili K. Transplant renal artery stenosis associated with acute cytomegalovirus infection: resolution following ganciclovir administration. Ren Fail. 2009;31:982-984.

13. Ansarin K, Bavil AS, Ghabili K, et al. Are Doppler ultrasonography parameters symmetric between the right and left kidney? Int $J$ Gen Med. 2010;3:371-373.

14. Farhoudi M, Mehrvar K, Aslanabadi N, Ghabili K, Baghmishe NR, Ilkhchoei F. Doppler study of cerebral arteries in hypercholesterolemia. Vasc Health Risk Manag. 2011;7:203-207.

15. Moneta GL, Edwards JM, Papanicolaou G, et al. Screening for asymptomatic internal carotid artery stenosis: duplex criteria for discriminating 60\% to 99\% stenosis. J Vasc Surg. 1995;21:989-994.

16. Grant EG, Benson CB, Moneta GL, et al. Carotid artery stenosis: grayscale and Doppler ultrasound diagnosis - Society of Radiologists in Ultrasound consensus conference. Ultrasound Q. 2003;19:190-198.

17. Ahn SS, Baker JD, Walden K, Moore WS. Which asymptomatic patients should undergo routine screening carotid duplex scan? Am J Surg. 1991;162:180-183. 
18. de Virgilio C, Toosie K, Arnell T, et al. Asymptomatic carotid artery stenosis screening in patients with lower extremity atherosclerosis: a prospective study. Ann Vasc Surg. 1997;11:374-377.

19. House AK, Bell R, House J, Mastaglia F, Kumar A, D’Antuono M. Asymptomatic carotid artery stenosis associated with peripheral vascular disease: a prospective study. Cardiovasc Surg. 1999; 7:44-49.

20. Pilcher JM, Danaher J, Khaw KT. The prevalence of asymptomatic carotid artery disease in patients with peripheral vascular disease. Clin Radiol. 2000;55:56-61.

21. Ascher E, DePippo P, Salles-Cunha S, Marchese J, Yorkovich W. Carotid screening with duplex ultrasound in elderly asymptomatic patients referred to a vascular surgeon: is it worthwhile? Ann Vasc Surg. 1999;13:164-168.

22. Cheng SW, Wu LL, Ting AC, Lau H, Wong J. Screening for asymptomatic carotid stenosis in patients with peripheral vascular disease: a prospective study and risk factor analysis. Cardiovasc Surg. 1999; 7:303-309.

23. Kurvers HA, van der GraafY, Blankensteijn JD, Visseren FL, Eikelboom BC; SMART Study Group. Screening for asymptomatic internal carotid artery stenosis and aneurysm of the abdominal aorta: comparing the yield between patients with manifest atherosclerosis and patients with risk factors for atherosclerosis only. J Vasc Surg. 2003;37:1226-1233.

24. Hegele RA. The pathogenesis of atherosclerosis. Clin Chim Acta. 1996;246:21-38.

25. Spence JD, Hegele RA. Noninvasive phenotypes of atherosclerosis: similar windows but different views. Stroke. 2004;35:649-653.

26. Crouse JR, Goldbourt U, Evans G, et al. Arterial enlargement in the atherosclerosis risk in communities (ARIC) cohort. In vivo quantification of carotid arterial enlargement. The ARIC Investigators. Stroke. 1994;25:1354-1359.

27. Miralles M, Corominas A, Cotillas J, Castro F, Clara A, Vidal-Barraquer F. Screening for carotid and renal artery stenoses in patients with aortoiliac disease. Ann Vasc Surg. 1998;12:17-22.

28. Simons PC, Algra A, Eikelboom BC, Grobbee DE, van der Graaf Y. Carotid artery stenosis in patients with peripheral arterial disease: the SMART study. SMART study group. J Vasc Surg. 1999;30:519-525.
29. Shirani S, Boroumand MA, Abbasi SH, et al. Preoperative carotid artery screening in patients undergoing coronary artery bypass graft surgery. Arch Med Res. 2006;37:987-990.

30. Shirani S, Shakiba M, Soleymanzadeh M, Esfandbod M. Can opium abuse be a risk factor for carotid stenosis in patients who are candidates for coronary artery bypass grafting? Cardiol J. 2010;17:254-258.

31. Tarzamni MK, Afrasyabi A, Farhoodi M, Karimi F, Farhang S. Low prevalence of significant carotid artery disease in Iranian patients undergoing elective coronary artery bypass. Cardiovasc Ultrasound. 2007;5:3.

32. Shakouri P, Nezami N, Tarzamni MK, Rashid RJ. The elusive link between high sensitivity $\mathrm{C}$-reactive protein and carotid subclinical atherosclerosis in coronary artery bypass grafting candidates: a crosssectional study. Cardiovasc Ultrasound. 2008;6:23.

33. Shah AM, Banerjee T, Mukherjee D. Coronary, peripheral and cerebrovascular disease: a complex relationship. J Indian Med Assoc. 2010;108:292-294.

34. Endo M, Kumakura H, Kanai H, et al. Prevalence and risk factors for renal artery stenosis and chronic kidney disease in Japanese patients with peripheral arterial disease. Hypertens Res. 2010;33:911-915.

35. Halliday A, Mansfield A, Marro J, et al. Prevention of disabling and fatal strokes by successful carotid endarterectomy in patients without recent neurological symptoms: randomised controlled trial. Lancet. 2004;363:1491-1502.

36. Chaturvedi S, Bruno A, Feasby T, et al. Carotid endarterectomy - an evidence-based review: report of the Therapeutics and Technology Assessment Subcommittee of the American Academy of Neurology. Neurology. 2005;65:794-801.

37. Halliday A, Harrison M, Hayter E, et al. 10-year stroke prevention after successful carotid endarterectomy for asymptomatic stenosis (ACST-1): a multicentre randomised trial. Lancet. 2010;376:1074-1084.

38. Ropper AH, Brown RH, editors. Adams and Victor's Principles of Neurology. 8th ed. New York: McGraw-Hill; 2005.
Vascular Health and Risk Management

\section{Publish your work in this journal}

Vascular Health and Risk Management is an international, peerreviewed journal of therapeutics and risk management, focusing on concise rapid reporting of clinical studies on the processes involved in the maintenance of vascular health; the monitoring, prevention and treatment of vascular disease and its sequelae; and the involvement of

\section{Dovepress}

metabolic disorders, particularly diabetes. This journal is indexed on PubMed Central and MedLine. The manuscript management system is completely online and includes a very quick and fair peer-review system, which is all easy to use. Visit http://www.dovepress.com/ testimonials.php to read real quotes from published authors. 